\title{
Standard addition strip for quantitative electrostatic spray ionization mass spectrometry analysis: Determination of caffeine in drinks.
}

\author{
Elena Tobolkina ${ }^{\mathrm{a}}$, Liang Qiao ${ }^{\mathrm{a}}$, Christophe Roussel ${ }^{\mathrm{b}}$, Hubert H. Girault ${ }^{\mathrm{a}, *}$ \\ a Laboratoire d'Electrochimie Physique et Analytique, Ecole Polytechnique Fédérale de Lausanne (EPFL), Station 6, CH-1015 Lausanne, Switzerland \\ ${ }^{\mathrm{b}}$ Section of Chemistry and Chemical Engineering/Institute of Chemical Sciences and Engineering, Ecole Polytechnique Fédérale de Lausanne, Station 6, \\ $\mathrm{CH}$-1015 Lausanne, Switzerland
}

\section{A R T I C L E I N F O}

Article history:

Received 12 May 2014

Received in revised form

3 July 2014

Accepted 9 July 2014

Available online 17 July 2014

Keywords:

Caffeine

Mass spectrometry

Quantitative analysis

Electrostatic spray ionization

\begin{abstract}
A B S T R A C T
Standard addition strips were prepared for the quantitative determination of caffeine in different beverages by electrostatic spray ionization mass spectrometry (ESTASI-MS). The gist of this approach is to dry spots of caffeine solutions with different concentrations on a polymer strip, then to deposit a drop of sample mixed with an internal standard, here theobromine on each spot and to measure the mass spectrometry signals of caffeine and theobromine by ESTASI-MS. This strip approach is very convenient and provides quantitative analyses as accurate as the classical standard addition method by MS or liquid chromatography.
\end{abstract}

(c) 2014 Elsevier B.V. All rights reserved.

\section{Introduction}

Many food and drinks with caffeine content are now commercially available. Consequently, there is a great interest for development of fast analytical tools to measure caffeine and other alkaloids, such as theobromine, theophylline and paraxanthine. These alkaloids have been found in more than 100 different plants and are widely used in the preparation of food, beverages and medicines with analgesic effect [1]. The most well known drinks containing caffeine are coffee and tea. Nowadays, these two beverages are the most consumed drinks all over the world [2]. Caffeine works as a natural drug to stimulate the central nervous and metabolic system [3]. It has positive influence, such as to prevent lung diseases and metabolic disorders [4]. However, its overconsumption can lead to caffeine overdose, in extreme cases to death [5]. The daily intake of caffeine is suggested to be less than $400 \mathrm{mg}$ [6]. Therefore, it is important to quantify caffeine in various food and drink in order to control its consumption and prevent caffeine intoxication.

Caffeine quantitative analyses have been performed with various analytical techniques, including high-performance liquid chromatography (HPLC) with ultraviolet (UV) detection [7-9], capillary electrophoresis [10], gas chromatography (GC) coupled to mass spectrometry (MS) [11], HPLC-MS [12,13], Fourier transform infra-red (FTIR) spectroscopy [14], high-performance thin-layer chromatography (HPTLC) [15] and etc. In addition to these widely used analytical methods,

\footnotetext{
* Corresponding author. Tel.: +41 21693 3145; fax: +41 216933667

E-mail address: hubert.girault@epfl.ch (H.H. Girault).
}

several ambient ionization MS techniques have been introduced for caffeine analysis, such as direct analysis in real time (DART) MS [16], probe electrospray ionization MS and low temperature plasma MS $[17,18]$. Using ambient ionization MS can avoid time-consuming sample preparation procedures, therefore highly suitable for high throughput analyses.

Recently, we have developed a new contactless ambient ionization technique called electrostatic spray ionization (ESTASI), where a droplet of a liquid containing analytes on a plastic substrate is ionized by application of a pulsating high voltage (HV) for MS detection [19]. The main advantage of ESTASI over other electrospray techniques is that the samples require minimal or no preparation, meaning that ESTASI can provide fast and real-time measurements whilst generating accurate data. To date, ESTASI has been successfully used to analyze protein/peptide dried on a plastic plate [19] or inside a porous matrix [20], to couple MS with capillary electrophoresis [19] and gel electrophoresis [20], to quickly characterize perfume [21] and perform MS imaging of biomolecules on a substrate[22].

In this work, ESTASI-MS is applied for a rapid quantitative analysis of caffeine in beverages with only a few sample pretreatment procedures. The quantitative analysis method is based on plastic strips containing spots of standards at different concentrations, and is named as standard addition strip-ESTASI-MS. The quantification of caffeine in various samples has been performed both with the standard addition strip-ESTASI-MS method and compared with classical standard addition methods by MS or LC. Proof of concept results have been obtained, indicating that this strip strategy can be applied for fast and accurate food analysis and quality control. 


\section{Material and methods}

\subsection{Chemicals and materials}

Caffeine ( $\geq 99 \%$ ) and theobromine ( $\geq 99 \%$ ) were obtained from Sigma-Aldrich (Steinheim, Germany). Methanol (99.9\%, HPLC grade) was purchased from Applichem GmbH (Darmstadt, Germany). Acetic acid (100\%) was obtained from Merck (Zug, Switzerland). All these reagents and materials were used as received without further purification. Black coffee, tea, and soft drinks (Coca-Cola $^{\mathrm{TM}}$, Coca-Cola Zero ${ }^{\mathrm{TM}}$, Nestea ${ }^{\mathrm{TM}}$ ) were purchased from the local store. Deionized (DI) water $(18.2 \mathrm{M} \Omega \mathrm{cm}$ ) was purified by an alpha Q Millipore system (Zug, Switzerland) and used for all experiments. Gelbond PAG film, $0.2 \mathrm{~mm}$ thickness, from Amersham Pharmacia Biotech AG (Uppsala, Sweden) was used as the insulating plate during ESTASI.

\subsection{Sample preparation}

Soluble coffee ( $2 \mathrm{~g}$ ) was diluted in $100 \mathrm{ml}$ of boiled water. Black tea leaves $(2 \mathrm{~g}$ ) were poured with $100 \mathrm{ml}$ of boiling water and filtered. Soft drinks (Coca-Cola ${ }^{\mathrm{TM}}$, Coca-Cola Zero ${ }^{\mathrm{TM}}$, Nestea Lemon $^{\mathrm{TM}}$ ) were decarbonized using the sonication bath. All liquid samples were diluted 50 times with an acidic solution (50\% methanol, $49 \%$ water and $1 \%$ acetic acid). In standard addition methods, pure caffeine of different concentrations was added into the diluted samples till a final concentration between 5 and $50 \mu \mathrm{g} /$ $\mathrm{ml}$. In all MS experiments, a fixed amount $(25 \mu \mathrm{l})$ of an aqueous solution containing $200 \mu \mathrm{g} / \mathrm{ml}$ of theobromine was added into $975 \mu \mathrm{l}$ of each diluted sample as an internal standard, giving a final concentration of $5 \mu \mathrm{g} / \mathrm{ml}$.

\subsection{High performance liquid chromatography quantitation of caffeine}

HPLC analyses of caffeine were performed on a Waters 1525 (Milford, MA, USA) apparatus equipped with a binary pump, a Rheodyne injector with a $5 \mu \mathrm{L}$ injection loop and a dual wave length UV detector 2487 . The compounds were separated on a $4.6 \mathrm{~mm}$ i.d. $\times 250 \mathrm{~mm}, 5 \mu \mathrm{m}$ particle reversed-phase Nucleodur $\mathrm{C}_{18}$ gravity column (Macherey-Nagel, AG, Switzerland). Methanol/ water $50 / 50(\mathrm{v} / \mathrm{v})$ was used as a mobile phase. Isocratic elutions were performed at a flow rate of $0.8 \mathrm{ml} / \mathrm{min}$. The column was operated at room temperature and the adsorption wavelength was set at $280 \mathrm{~nm}$. The analysis time was $7 \mathrm{~min}$. $20 \mu \mathrm{l}$ of black tea or black coffee infusion previously diluted 50 times in the acidic solution, with or without pure caffeine additions (from 5 to $50 \mu \mathrm{g}$ / $\mathrm{ml}$ ) were injected. For each sample, experiments were repeated three times. Caffeine in the sample was identified by comparing its retention time with that of pure caffeine standard.

\subsection{ESTASI-MS}

A linear ion trap mass spectrometer of Thermo LTQ Velos (Reinach, Switzerland) with an ion transfer capillary modified into an "L" shape [21] was used for ESTASI-MS. Electrospray voltage of the LTQ Velos was set as $0 \mathrm{~V}$. An enhanced ion trap scanning rate $(10,000 \mathrm{~m} / z$ units $/ \mathrm{s})$ was used for the MS analysis. During the experiments, the commercial ion source of the instrument was replaced by an ESTASI ion source. $5 \mu \mathrm{l}$ of sample in the acidic solution (50\% methanol, $49 \%$ water and $1 \%$ acetic acid) was loaded on top of a polymer insulating plate by Eppendorf pipette. An electrode was placed behind the droplet and under the insulating plate. The distance between the MS inlet and the droplet was around $2 \mathrm{~mm}$. By applying HV $(9 \mathrm{kV})$ to the electrode, the droplet became polarized and as soon as the charge was large enough at the tip of the droplet, a spray of charged microdroplets occurred. When grounding the electrode, a spray of counter charges took place to re-establish the electroneutrality of the droplet. By applying a pulsating square wave $\mathrm{HV}(0-9 \mathrm{kV})$ at a given frequency, alternating spray of cations and anions took place. The square wave HV was amplified from a function generator by an amplifier (10HVA24-P1, HVP High Voltage Products GmbH, Martinsried/Planegg, Germany). A digital oscilloscope was used to monitor current and HV pulse. All mass spectra were recorded in positive ion mode. Data analysis was performed by Xcalibur Qual Browser (ThermoFisher Scientific, Reinach, Switzerland). More detailed information on ESTASI can be found elsewhere [19].

\subsection{Standardization on ESTASI-MS}

To determine the concentration of caffeine in unknown sample, theobromine $(5 \mu \mathrm{g} / \mathrm{ml})$ was mixed with pure caffeine of various concentrations $(5-50 \mu \mathrm{g} / \mathrm{ml})$ in an acidic solution containing $50 \%$ methanol, $49 \%$ water and $1 \%$ acetic acid. The mixtures were analyzed by ESTASI-MS, and the ratios of the peak intensities of caffeine and theobromine were plotted as a function of the caffeine concentration to demonstrate the quantitative analysis performance of ESTASI-MS.

\subsection{Standard addition calibration by ESTASI-MS}

The method of standard addition by ESTASI-MS was performed by adding small amounts of pure caffeine into the diluted samples in the acidic solution that contained also the internal standard of theobromine for ESTASI-MS analyses. Peak intensities of caffeine and theobromine from mass spectra were used for calculation. The experiments for each sample were repeated several times for accurate calibration and to obtain the standard deviation (SD). The calibration curves and figures were plotted using IGOR Pro (Version 6.00 for Macintosh, WaveMetrics, Lake Oswego, OR, USA).

\subsection{Standard addition strip-ESTASI-MS}

Arrays of wells ( $1 \mathrm{~mm}$ diameter, $2 \mathrm{~mm}$ depth) were drilled on a plastic strip. $5 \mu \mathrm{l}$ of pure caffeine of known concentration $(5-50 \mu \mathrm{g} / \mathrm{ml})$ was deposited in the wells and left to dry. The strip containing the dried spots of pure caffeine was placed under the MS inlet. $5 \mu$ l of a diluted sample mixed with theobromine in the acidic solution was deposited carefully to fully cover the drilled well in order to extract all the dry caffeine just before ESTASI-MS analysis. The electrode and ion transfer capillary were set in such a way to be in line with the center of the drilled hole to achieve good reproducibility. The obtained signal intensities of caffeine and theobromine were used to calculate the caffeine amount in the sample.

\section{Results and discussion}

\subsection{Quantitative analysis from droplets of standard solution by ESTASI-MS.}

ESTASI-MS is very sensitive in the detection of trace amount of caffeine. The limit of detection (LOD) was found as $51 \mathrm{nM}$ (10 ng/ml) (see Supporting information (SI)-1). To demonstrate the quantitative analysis performance, a series of standard solution was prepared in 50\% methanol, $49 \%$ water and $1 \%$ acetic acid containing pure caffeine at different concentrations $(5-50 \mu \mathrm{g} / \mathrm{ml})$ and a constant amount of internal standard $(5 \mu \mathrm{g} / \mathrm{ml})$ of theobromine. Theobromine was selected as the internal standard since it has a structure similar to that of caffeine. $5 \mu$ l of each solution was 
deposited on an insulating plate for ESTASI-MS analysis. As shown in Fig. 1, both caffeine and theobromine were detected as single protonated $\left([\mathrm{M}+\mathrm{H}]^{+}\right)$ions in a positive ion mode. The peak at $\mathrm{m} / \mathrm{z}$ 195.1 corresponds to caffeine and the peak at $\mathrm{m} / z 181.2$ corresponding to theobromine (see Fig. 1). The peak intensities ratios between caffeine and theobromine were calculated to plot as a function of caffeine concentration. The calibration showed a good linear regression $(y=0.2528 x+0.1403)$ with a determination coefficient $R^{2}$ of 0.998 (see Supporting information (SI)-2), showing that ESTASI-MS is a technique suitable for quantitative analysis, and that the theobromine is a suitable internal standard for caffeine quantification by MS.

\subsection{Standard addition calibration of caffeine in various drinks by ESTASI-MS.}

The method of standard addition was used to calculate caffeine concentrations in different drinks by ESTASI-MS. All the drinks were diluted 50 times in the acidic solution and then mixed with different concentrations of pure caffeine $(5-50 \mu \mathrm{g} / \mathrm{ml})$ and the internal standard of theobromine at fixed concentration $(5 \mu \mathrm{g} / \mathrm{ml})$. The concentrations of added pure caffeine were selected in a way that they were close to the concentration of caffeine in the test sample for accurate quantifications. $5 \mu \mathrm{l}$ of each mixture was deposited on a plastic strip (Gelbond PAG film) and analyzed directly by ESTASI-MS. In the example of coffee analysis, the peak intensity ratios of caffeine and theobromine were plotted as a function of the concentration of added pure caffeine to get a linear regression equation $(y=0.0981 x+0.5329)$ with a determination coefficient $R^{2}$ of 0.995 (see (SI)-3). This equation was used to calculate the concentration of caffeine in the coffee as $272 \mu \mathrm{g} / \mathrm{ml}$.

Similarly, soft drinks, such as Coca-Cola ${ }^{\mathrm{TM}}$, Coca-Cola Zero ${ }^{\mathrm{TM}}$, and Nestea ${ }^{\mathrm{TM}}$, as well as tea extracts were also analyzed using ESTASI-MS by the standard addition method. The data obtained were plotted to calculate the caffeine concentrations (see Supporting information (SI)-3), and the obtained caffeine concentration in different samples are summarized in Table 1.

For soft drinks, the caffeine concentrations obtained using the ESTASI-MS were compared with the values reported by the manufacturer. For the black coffee and tea infusions, the caffeine concentration obtained by ESTASI-MS were compared with results from LC experiments (see SI-3), since it could vary from sample to sample depending on the preparation procedures. As shown in Table 1, the caffeine concentrations obtained by ESTASI-MS are in good agreement with the reported values and the ones by LC measurements, indicating that the ESTASI-MS is an efficient approach for caffeine quantitative analysis. With the experiments repeated three times for

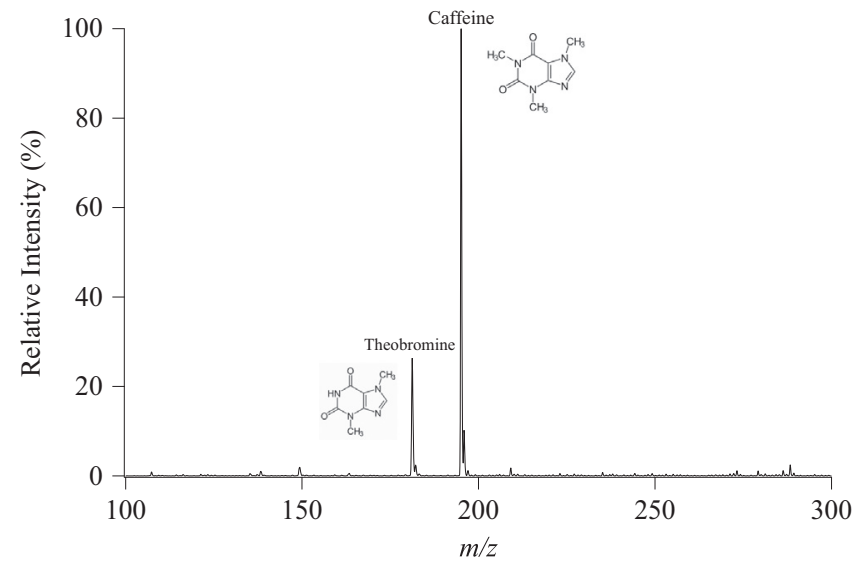

Fig. 1. Positive mode ESTASI-MS signal of $10 \mu \mathrm{g} / \mathrm{ml}$ caffeine solution mixed with $5 \mu \mathrm{g} / \mathrm{ml}$ of theobromine in $50 \%$ methanol, $49 \%$ water and $1 \%$ acetic acid
Table 1

Caffeine concentrations in the samples of different beverages calculated by the methods of standard addition $\left(C_{\mathrm{MSD}}\right)$ and standard addition strip $\left(C_{\text {strip }}\right)$ using ESTASI-MS in comparison with the reference values from manufacturer or standard LC experiments.

\begin{tabular}{lrrl}
\hline Sample & $\boldsymbol{C}_{\text {MSD }}(\boldsymbol{\mu g} / \mathbf{m l})^{\mathrm{a}}$ & $\boldsymbol{C}_{\text {Strip }}(\boldsymbol{\mu g} / \mathbf{m l})^{\mathrm{a}}$ & $\boldsymbol{C}(\boldsymbol{c} \mathbf{g} / \mathbf{m l})$ \\
\hline Black coffee infusion & $271.61 \pm 0.32$ & $295.65 \pm 0.24$ & $281.81 \pm 0.38^{\mathrm{b}}$ \\
Black tea infusion & $258.18 \pm 0.52$ & $259.98 \pm 0.01$ & $245.21 \pm 0.62^{\mathrm{b}}$ \\
Coca-Cola Zero & $97.36 \pm 0.17$ & $98.17 \pm 0.21$ & $96^{\mathrm{c}}$ \\
Coca-Cola Classic & $90.18 \pm 0.70$ & $95.50 \pm 0.11$ & $95^{\mathrm{c}}$ \\
Ice tea & $67.84 \pm 0.41$ & $70.88 \pm 0.13$ & $68-72^{\mathrm{c}}$ \\
\hline
\end{tabular}

a Calculated as undiluted drink.

${ }^{\mathrm{b}}$ Concentration of caffeine obtained by the standard LC method.

${ }^{\mathrm{c}}$ Reported concentration from the manufacturer.

all examined samples, the standard deviations were calculated and presented in Table 1. Between the experiments, the MS ion transfer capillary was washed in order to prevent carry over of caffeine that can adsorb on the inner walls of the capillary.

The main advantage of using standard addition method is to avoid matrix effect from complex samples. In a real drink sample, many molecules may be ionized that could influence the ionization of caffeine and theobromine. This influence is obvious when the standard addition calibration was performed with soft drinks, coffee or tea. The suppression in food samples was previously reported $[23,24]$.

\subsection{Method of standard addition using strip-ESTASI-MS.}

We present here a method of calibration based on the preparation of a plastic plate containing a series of dry spots of the analyte of interest to be examined by ESTASI-MS. A plastic strip of appropriate length with wells of $1 \mathrm{~mm}$ in diameter was employed. $5 \mu \mathrm{l}$ droplets containing caffeine at different concentrations in the range of 5$50 \mu \mathrm{g} / \mathrm{ml}$ in water were deposited on the wells and dried under ambient conditions. The wells were used to help localization and controlled sample deposition. The plastic strip can be directly used for caffeine quantification or stored for future tests.

Using the strip as an insulating plate for ESTASI, quantitative analysis of caffeine in drinks can be directly performed without a preparation step of mixing the sample with the dried pure caffeine, as illustrate in Scheme 1 . The mixture $(5 \mu \mathrm{l})$ containing constant amount of theobromine and a test sample in acidic solution was loaded on each dried spot. The dried caffeine on the spot was dissolved, immediately extracted and ionized together with the caffeine in the test sample and theobromine for ESTASI-MS analysis. It was verified that the previously dried pure caffeine was fully extracted from the surface of a strip during ESTASI-MS analyses (see SI-4). The spots were analyzed in the order of increasing the concentration of the previously dried caffeine. All mass spectra were recorded in positive ion mode. The intensities of caffeine and theobromine were detected by MS and further used to plot the calibration curve (see Fig. 2). When the test sample was black coffee infusion, analytical response of caffeine showed a good linear correlation $(y=0.0191 x+0.5647)$ and a determination coefficient $R^{2}$ of 0.995 . With this calibration curve, the caffeine amount was found by strip-ESTASI-MS as $1478 \mathrm{ng}$, corresponding to a concentration of caffeine in coffee as $295 \mu \mathrm{g} / \mathrm{ml}$.

As it can be observed, the equation of linear regression line and a determination coefficient for the strip-ESTASI-MS standard addition is quite similar to the one for normal standard addition, meaning that the method of strip-ESTASI-MS could be used as a convenient, rapid and efficient method for calculating caffeine concentrations in different beverages. The caffeine concentrations in different beverages obtained by the strip-ESTASI-MS are also summarized in Table 1. The values are in a good agreement with the reported values and 


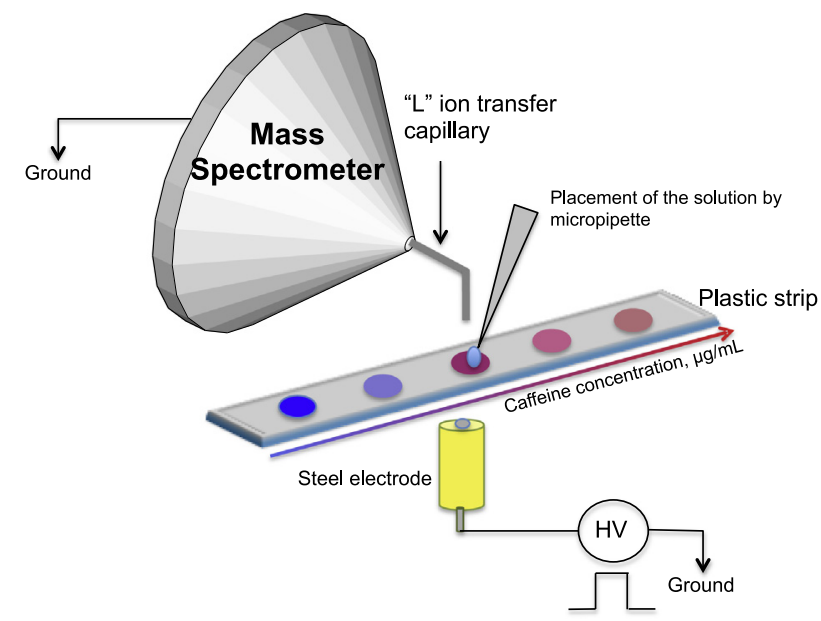

Scheme 1. Schematic representation of the electrostatic spray ionization from a plastic strip containing the dried droplets of caffeine spots, HV: high voltage.

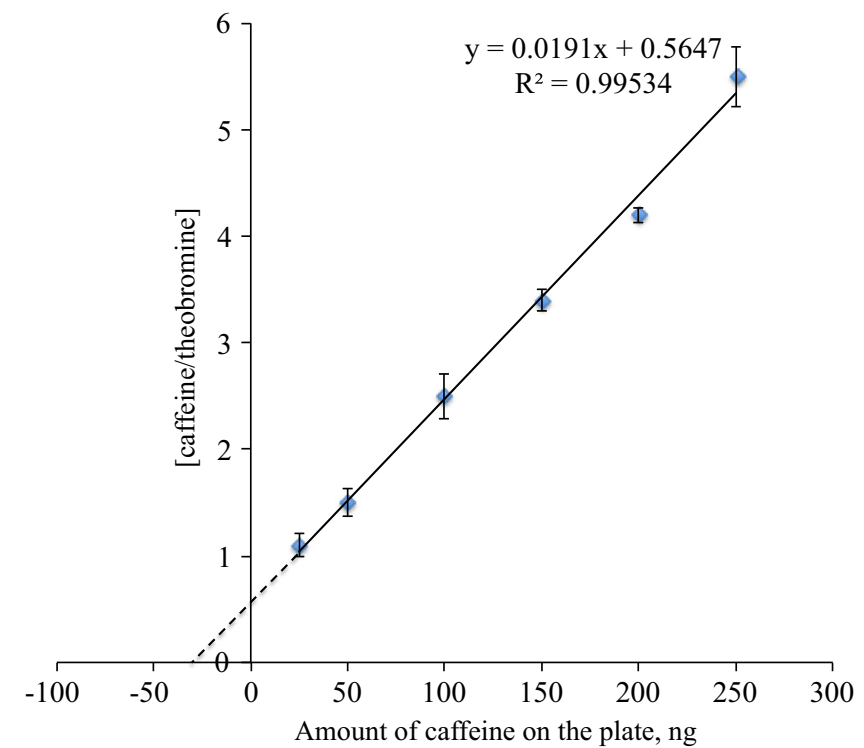

Fig. 2. Standard plot of caffeine/theobromine mass spectral signal intensity ratio as a function of the amount of caffeine in the dried spot using the strip-ESTASI-MS. The standard deviation was calculated from three experiments and shown as the error bar. The sample was black coffee.

those from the standard addition method without strip. The plotted curves of caffeine/theobromine mass spectral intensity ratio in the presence of different matrices (soft drinks and tea infusion) are presented in SI-4. It should be noted that during the analysis of different beverages, not only caffeine and theobromine were detected by MS, but also other compounds present in the sample. For instance the mass spectra recorded in a positive ion mode by ESTASI-MS of Nestea Lemon is presented in SI-4.

\subsection{Quantification of caffeine in saliva by strip-ESTASI-MS.}

The strip-ESTASI-MS standard addition method was applied for caffeine quantification in saliva. The saliva was collected at different times from a healthy volunteer after drinking a cup of coffee. The collected samples of saliva were spiked with constant amount $(5 \mu \mathrm{g} / \mathrm{ml}$ final concentration) of internal standard. The concentration of caffeine in each sample was analyzed using the standard addition strip-ESTASI-MS. The change in caffeine concentration with time is presented on Fig. 3.

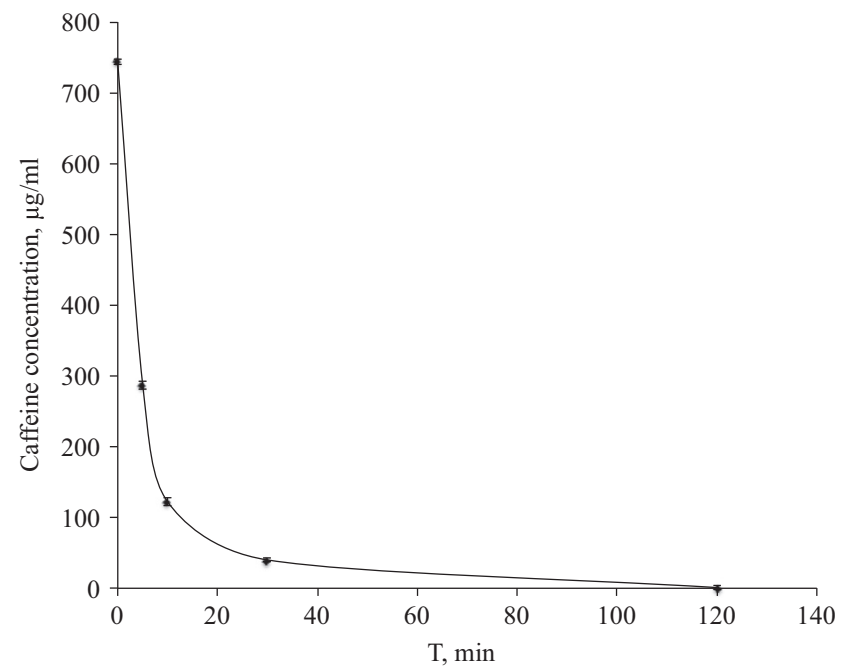

Fig. 3. Caffeine concentration in saliva $0,5,10,30,120$ min after drinking coffee determined by strip-ESTASI-MS standard addition method. The standard deviation was calculated from three experiments and shown as the error bar.

As it is seen from Fig. 3, the caffeine concentration decreased with time as expected. The concentration of caffeine in saliva directly after drinking the black coffee infusion from the local cafeteria was $743 \mu \mathrm{g} / \mathrm{ml}$ (see SI-5). In $5 \mathrm{~min}$ the concentration reduced to $287 \mu \mathrm{g} / \mathrm{ml}$, in $10 \mathrm{~min}$ to $122 \mu \mathrm{g} / \mathrm{ml}$, and in $30 \mathrm{~min}$ to $30 \mu \mathrm{g} / \mathrm{ml}$. Even after $2 \mathrm{~h}$, the caffeine was still presented in the saliva and detected by ESTASI-MS with an amount of $1 \mu \mathrm{g} / \mathrm{ml}$, which is much higher than the LOD of ESTASI-MS to caffeine of $10 \mathrm{ng} / \mathrm{ml}$ as explained before. We would expect to apply this method for the fast analysis of caffeine not only in saliva, but also in blood, urine or samples of interests in the view of forensic science.

\section{Conclusions}

ESTASI-MS has been used as a fast quantitative technique for caffeine analysis. This new ambient ionization method can be used for fast and high-throughput quantification of different compounds in samples of interest. The method of standard addition by ESTASI-MS based on a strip containing dried spots of caffeine had been used for caffeine analysis in different beverages, such as soft drinks (Coca-Cola ${ }^{\mathrm{TM}}$, Coca-Cola Zero ${ }^{\mathrm{TM}}$, Ice tea), coffee and tea extract. The calculated values were compared with the reported ones, and are in a good agreement. The proposed standard addition strip is in low cost, for single use and can be prepared in any laboratory. This new method can be applied in numerous research fields, such as food quality control.

\section{Appendix A. Supporting information}

Supplementary data associated with this article can be found in the online version at http://dx.doi.org/10.1016/j.talanta.2014.07.024.

\section{References}

[1] V. Kumar, G.A. Ravishankar, Food Rev. Int. 25 (2009) 175-197.

[2] P. Nawrot, S. Jordan, J. Eastwood, J. Rotstein, A. Hugenholtz, M. Feeley, Food Addit. Contam. A 20 (2003) 1-30.

[3] P.J. Rogers, C. Dernoncourt, Pharmacol. Biochem. Behav. 59 (1998) 1039-1045.

[4] A. Kugelman, M. Durand, Pediatr. Pulm. 46 (2011) 1153-1165.

[5] S. Kerrigan, T. Lindsey, Forens. Sci. Int. 153 (2005) 67-69.

[6] J. Brown, N. Kreiger, G.A. Darlington, M. Sloan, Am. J. Epidemiol. 153 (2001) $815-820$. 
[7] M.S. Bispo, M.C.C. Veloso, H.L.C. Pinheiro, R.F.S. De Oliveira, J.O.N. Reis, J.B. de Andrade, J. Chromatogr. Sci. 40 (2002) 45-48.

[8] B.L. Madison, W.J. Kozarek, C.P. Damo, J. Assoc. Off. Anal. Chem. 59 (1976) $1258-1261$.

[9] A.R.D. Sena, Food Technol. Biotechnol. 49 (2011) 413-423.

[10] C.S. Bizzotto, A.D. Meinhart, C.A. Ballus, G. Ghiselli, H.T. Godoy, Food Sci. Tech. -Braz. 33 (2013) 186-191.

[11] L. Svorc, Int. J. Electrochem. Sci. 8 (2013) 5755-5773.

[12] P.R. Gardinali, X. Zhao, Environ. Int. 28 (2002) 521-528.

[13] M. Aranda, G. Morlock, Rapid Commun. Mass Spectrom. 21 (2007) 1297-1303.

[14] B.R. Singh, M.A. Wechter, Y.H. Hu, C. Lafontaine, Biochem. Educ. 26 (1998) 243-247.

[15] M.D. Misra H., B.K. Mehta, M. Soni, D.C. Jain, Int. J. Green Pharm. 3 (2009) 47-51.

[16] L. Wang, P.Y. Zhao, F.Z. Zhang, A.J. Bai, C.P. Pan, J. Assoc. Off. Anal. Int. 96 (2013) 353-356.
[17] M.J. Ford, M.A. Deibel, B.A. Tomkins, G.J. Van Berkel, Anal. Chem. 77 (2005) 4385-4389.

[18] J.D. Harper, N.A. Charipar, C.C. Mulligan, X.R. Zhang, R.G. Cooks, Z. Ouyang, Anal. Chem. 80 (2008) 9097-9104.

[19] L. Qiao, R. Sartor, N. Gasilova, Y. Lu, E. Tobolkina, B.H. Liu, H.H. Girault, Anal. Chem. 84 (2012) 7422-7430.

[20] L. Qiao, E. Tobolkina, B. Liu, H.H. Girault, Anal. Chem. 85 (2013) 4745-4752.

[21] E. Tobolkina, L. Qiao, G.B. Xu, H.H. Girault, Rapid Commun. Mass Spectrom. 27 (2013) 2310-2316.

[22] T.E. Qiao L., A. Lesch, A. Bondarenko, X. Zhong, B. Liu, H.M. Pick, H. Vogel, H.H. Girault, Anal. Chem. 86 (2014) 2033-2041.

[23] R. King, R. Bonfiglio, C. Fernandez-Metzler, C. Miller-Stein, T. Olah, J. Am. Soc. Mass Spectrom. 11 (2000) 942-950.

[24] D. Perrone, C.M. Donangelo, A. Farah, Food Chem. 110 (2008) 1030-1035. 